DOI: 10.20472/IAC.2018.043.037

\author{
ANA RADINA \\ Faculty of Law, University of Split, Croatia
}

\title{
GUARDIANSHIP AS A MEANS OF PROTECTION OF ADULT PERSONS WITH MENTAL DISORDERS IN THE CROATIAN FAMILY LAW - A NEED FOR A CHANGE
}

\begin{abstract}
:
The deprivation of legal capacity and guardianship have traditionally been used as means of protection of persons with mental disorders who, due to their condition, are not capable of taking care of their own needs, rights and interests or otherwise jeopardise other people's rights and interests. However, the institute of guardianship in Croatia has long been burdened with unresolved issues and it had undergone through significant changes in the last few years.

Inter alia, the complete deprivation of legal capacity was intended to be implemented as an exception, while the partial deprivation was supposed to be a rule. The situation in practice was just the opposite and the statistics show that of the total number of persons deprived of legal capacity nearly $90 \%$ of them were completely deprived of their legal capacity and placed under plenary guardianship. The principle of individualised approach was obviously not applied appropriately but neither did the most recent family law reform in 2015 address the issue in an adequate manner.

The United Nations Convention on the rights of persons with disabilities obliges its states parties, including Croatia, to provide for additional protective measures that can be individually adapted to every person's needs. Hence, the guardianship should not be the only means of helping an adult with a mental disorder. Croatian legislator attempted to fulfil that obligation by simply abolishing the possibility of complete deprivation of legal capacity and the maintaining of the partial deprivation. The mere elimination of the substitute decision-making did not bring the necessary individualisation and differentiation of the system of protection for persons with mental disorders because it does not take into account the specific situation of those persons who are not capable of any form of meaningful participation in the society, or of any form of contact with other people. The insight into the Croatian courts' case-law following the latest legislative changes leads to the same conclusion the protection of such a person is formally exercised through the partial deprivation of legal capacity, however, when the judge states in their decision all the areas in which that person cannot act independently, it becomes clear that it is essentially a complete deprivation of legal capacity. Reasons for optimism can be found in the announced new Family act that is expected to bring more elaborated approach, including the new level of protection for adults with mental disorders through the mechanism of supported decision-making.
\end{abstract}

\section{Keywords:}

persons with mental disorders; protection; guardianship; substitute decision-making; family law reform 